\title{
Study the rheological properties of waxy oil with modified pour point depressants for the South Turgai oil field in Kazakhstan
}

\author{
S.S. Kozhabekov ${ }^{1, *}$, A.A. Zhubanov ${ }^{1}$, and Zh. Toktarbay ${ }^{1,2, *}$ \\ ${ }^{1}$ Kazakh-British Technical University JSC, Chemical Engineering Department, Tole bi 59, Almaty, Republic of Kazakhstan \\ ${ }^{2}$ Al-Farabi, Kazakh National University, Faculty of Chemistry and Chemical Technology, Department of Analytical, Colloidal \\ Chemistry and Technology of Rare Elements, Al-Farabi avenue 71, Almaty, Republic of Kazakhstan
}

Received: 26 September 2018 / Accepted: 14 January 2019

\begin{abstract}
This work describes the performance of poly(ethylene-co-vinyl acetate) (EVA) copolymer and modified poly(ethylene-co-vinyl acetate) (EVA-M) as pour point reducer. Commercially available EVA copolymer modified with sodium hydroxide in methanol. Partially hydrolyzed EVA was obtained and Fourier Transform InfraRed (FTIR) analysis of the modified EVA was recorded. The modified and unmodified EVA was used to crude oil of South Turgai, Kazakhstan, in order to improve the flowability of the crude oil. According to the rheological behavior of oils in the South Turgai, the findings showed that modified EVA lowered the dynamic viscosity greater compared to unmodified EVA and heat treatment. Dynamic viscosities and yield points of different oils with various temperatures with using EVA and EVA-M were studied systematically. Finally microphotograph of crystal structures two oils with using EVA and EVA-M, under same conditions, were compared and discussed.
\end{abstract}

\section{Introduction}

Kazakhstan is one of the oil-rich countries in the world. However, Kazakhstan's crude oil contains a high proportion of wax, which leads to slowing the flow of oil. For instance, transportation of crude oil of South Turgai oil field via pipeline to long distance precipitation of wax occurs which can block the pipeline, which in turn is expensive to repair [1]. Wax deposition is the most important problem, blocking the flow of hydrocarbons liquids as they are cooled [2]. At high temperatures and pressures, any waxes within the oil are in solution. As crude oil temperature drops, wax begins to precipitate from the crude oil, usually in the forms of needles and plates [3, 4].

The key characteristic in the wax deposition process is Wax Appearance Temperature (WAT), or cloud point, at which temperature the first wax crystals begin to precipitate from the crude oil. The WAT can be as high as $50{ }^{\circ} \mathrm{C}$ for some sorts of oil depending on the pressure, oil composition and bubble point [5].

There are many impact factors for the wax deposition process: the crude oil compositions, distribution of the paraffin molecules, the temperature of oil, the temperature dissimilarity between the oil and the pipe wall, the deposition time, the flow rate, etc. [6].

\footnotetext{
* Corresponding authors: skozhabekov.49@mail.ru; zhexenbek.toktarbay@gmail.com
}

Different methods of inhibition of wax deposition and asphaltene precipitation [7] have been used these days such as the heat insulation of subsea pipelines, the internal coating of pipelines with plastics, etc. However, the use of chemical inhibitors is one of the most effective means. Usually three types of chemicals are used: wax inhibitors or wax crystal modifiers, detergents, dispersants. A significant number of polymeric compounds such as poly alkyl acrylates and methacrylate copolymers, alkyl esters of styrenemaleic anhydride copolymers, alkyl acylate-alkyl maleate copolymers, ethylene-vinyl acetate copolymers; alkyl fumarate-vinyl acetate copolymers are some of the flow improvers for waxy crude oil $[8,9]$. Until now, the inhibition mechanism and the influence of polar oil components are not well understood.

EVA copolymers are the most commonly used polymeric wax inhibitors and Pour Point Depressants (PPDs). Researchers studied the EVA copolymers as PPD and flow improver for many crude waxy oils [10-13]. In order to further increase the effectiveness of EVA copolymers, some researchers modified EVA copolymer with alcohols and grafted polymers $[14,15]$

In this research, we modified EVA copolymer with alkali-catalyzed alcoholysis and copolymer hydrolysis degree of $5 \mathrm{~mol} . \%$ obtained and characterized. The obtained modified EVA copolymer tested in five different crude oils with various wax content. 


\section{Materials and methods}

\subsection{Materials}

Poly(ethylene-co-vinyl acetate) (EVA), with 25 wt.\% vinyl acetate content, purchased by "Sigma-Aldrich" was used without further purification. Toluene from "Sigma-Aldrich" was used without further purification. Methanol bought from "Sigma-Aldrich" was used without further purification. Sodium hydroxide of "Sigma-Aldrich" was used without further purification. Hydrochloric acid was used without purification.

\subsection{Modification of ethylene-co-vinyl acetate polymers with bases}

In a three-necked round bottom flask fitted with a reflux condenser, a thermometer, a magnetic stirrer, $2.0 \mathrm{~g}$ of EVA-25 copolymer was dissolved in $30 \mathrm{~mL}$ of toluene. After that, $1 \mathrm{~mL}$ of $2 \%$ solution of sodium hydroxide in methanol was added to the solution of the copolymer. Partial hydrolysis reaction proceeds according to the following scheme [16]:

The reaction was carried out at $80{ }^{\circ} \mathrm{C}$ for $30 \mathrm{~min}$. Then, the polymer was precipitated into methanol, filtered and dried in vacuum at $50^{\circ} \mathrm{C}$ until constant weight. Under these conditions the modified EVA copolymer obtained with hydrolysis degree of $5 \mathrm{~mol} . \%$.

\subsection{Pour point determination}

The methodology used for the determination of oil pour points was based on an adaptation of the ASTM D-97 and Method 5853.

\subsection{Apparent viscosity and shear stress}

The rheological behavior of the crude oil and oil mixtures were studied using rheometer Rheolab QC by software Rheoplus (Anton Paar). Apparent viscosity and shear stress were measured on the rheometer.

The model of the viscometer is Rheolab $\mathrm{QC}+$ with a temperature-controlled cylinder measuring system DGR$42(12 \mathrm{~mL})$, dual slot gap, and measuring cylindrical element CC-17 (5 mL). Measurements of the apparent viscosity and shear stress were performed in a linear temperature change with cooling rate of $25^{\circ} \mathrm{C} / \mathrm{h}$ at a constant shear rate equal to $10 \mathrm{~s}^{-1}$, and ramp shear rate (from $0 \mathrm{~s}^{-1}$ to $100 \mathrm{~s}^{-1}$ ) at constant temperature. Analyzing the curve, we determined the transition temperature of a Newtonian fluid into a non-Newtonian, non-Newtonian fluid ratio, transition rate, critical shear stress and apparent viscosity. Data on shear stress and apparent viscosity depending on shear rate was analyzed with Rheoplus Software. During the analysis of rheological curves (dependence of shear stress $\tau$ on shear rate) we used the Newton, Ostwald and the Herschel-Bulkley models.

\subsection{Fourier Transform InfraRed (FTIR)-analysis}

FTIR analysis was carried out on the spectrometer Nicolet 5700 FT-IR.

\section{Results and discussion}

The following waxy crude oils of South Turgay were examined on their rheological characteristics:

1. Akshabulak oil;

2. Kumkol oil;

3. Konys-Bektas oil;

4. Aschysay oil.

General characteristics for these oils are given in Table 1.

\subsection{Fourier Transform InfraRed (FTIR)-analysis of modified EVA copolymer}

FTIR analysis of modified and non-modified EVA copolymer was recorded.

Figure 1 shows the FTIR spectrum of EVA copolymer. Characteristic absorption bands of the copolymer EVA are in:

- $1735 \mathrm{~cm}^{-1}$, corresponding to the absorption of the stretching vibrations of $\mathrm{C}=\mathrm{O}$ carbonyl group in esters; - 2915 and $2847 \mathrm{~cm}^{-1}$, relating to the absorption of the stretching vibrations of $\mathrm{CH}_{3}$ groups and $-\mathrm{CH}_{3}-\mathrm{CH}_{2}$-ester groups.

Figure 1 (bottom) represents the FTIR spectrum of partially hydrolyzed ethylene-vinyl acetate copolymer. There are a reduction of band intensity in the range of 1735-1738 $\mathrm{cm}^{-1}$ - stretching vibrations of the carbonyl group $-\mathrm{C}=\mathrm{O}$ in esters and an appearance in the spectrum of the hydrolyzed EVA of a wide absorption band of $3236 \mathrm{~cm}^{-1}$, corresponded to the stretching vibrations of the $-\mathrm{OH}$ group.

Moreover, a reduction of the intensity of the absorption bands in the 2915 and $2847 \mathrm{~cm}^{-1}$, related to the absorption of the stretching vibrations of $\mathrm{CH}_{3}-$ groups and $-\mathrm{CH}_{3}-$ $\mathrm{CH}_{2}$-ester groups, and a strong reduction in the intensity of the absorption band of $1236 \mathrm{~cm}^{-1}$ in the spectrum of the initial EVA, corresponded to absorption band of fluctuations with regard $\mathrm{C}-\mathrm{O}$ group in acetate are observed.

\subsection{Influence of modified EVA on the pour points of waxy crude oils}

The PPD that was injected into oil disperse system modifies formed crystals of paraffin and regulates the structure of oil dispersion by means of increasing its aggregative stability. According to the results of experiment, modified EVA greatly influenced on the pour points of waxy crude oil.

Compared to the original ethylene-vinyl acetate copolymer, the chemical structure of modified EVA displays more polarity due to the presence of hydroxyl groups, which promote better disarrangement during wax crystallization process [18].

Table 2 shows WTA change of crude oils and oil mixtures when heat-treated and treated with additives. As it can be seen from the table, modified additive has high 
Table 1. General characteristics crude oils of South Turgay oil field [17].

\begin{tabular}{llcccccccc}
\hline No & \multicolumn{1}{c}{ Crude oil } & $\begin{array}{c}\mathrm{d}_{4}{ }^{20} \\
\left(\mathrm{~kg} / \mathrm{m}^{3}\right)\end{array}$ & $\mathrm{PP}\left({ }^{\circ} \mathrm{C}\right)$ & $\begin{array}{c}\text { Wax } \\
(\%)\end{array}$ & $\begin{array}{c}\text { Asphalt. } \\
(\%)\end{array}$ & $\begin{array}{c}\text { Resins } \\
(\%)\end{array}$ & \multicolumn{3}{c}{ Fraction $(\%)$} \\
\hline 1 & Kumkol & 810.4 & 12 & 14.4 & 0.1 & 7.6 & 29 & 49 & 59 \\
2 & Akshabulak & 829.7 & 21 & 14.3 & 0.6 & 8.6 & 29 & 48 & 58 \\
3 & Konys-Bektas & 874.4 & 24 & 16.5 & 2.0 & 7.1 & 15 & 33 & 47 \\
4 & Aschysay & 878.2 & 21 & 20.1 & 1.3 & 9.2 & 20 & 39 & 51 \\
\hline
\end{tabular}

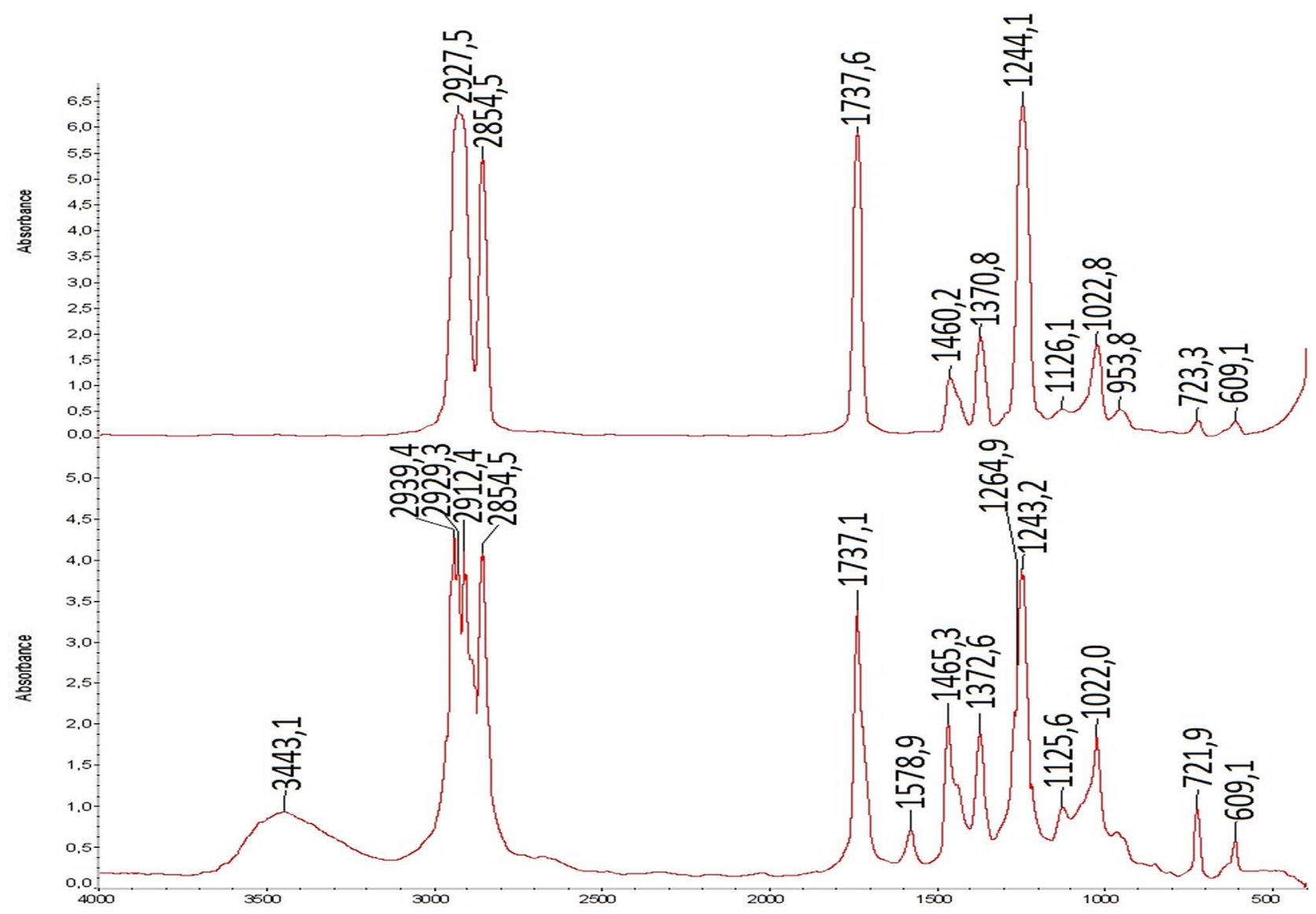

Fig. 1. FTIR spectrum of EVA copolymer and partially hydrolyzed EVA copolymer (bottom).

performance and this magnitude is stable for different types of oil.

\subsection{Impact on inhibition degree of waxy crude oils}

Experimental examination of inhibition degree was carried out by means of "cold finger" and it revealed that modified ethylene-vinyl acetate copolymer can be introduced as an effective wax inhibitor, not only as PPD. Data on inhibition degree of highly paraffinic oil is showed in Table 3.

Polymeric additives affect by different way with the formation of loosely bound clusters. Mechanism of wax inhibitors' action includes the hindering the nucleation and crystals formation processes. Thus, at or below the cloud point, the non-polar (wax-like crystalline) part of the molecule of PPD co-crystallizes with wax crystals, whereas the polar (amorphous) part creates a barrier to the formation of interlocking wax network and inhibit the process of crystallization [19]. This prevents the formation of structured grids of wax crystals on the pipe wall, thereby inhibiting the process of paraffin deposition on the walls of oil pipelines. Inhibitors or wax crystal modifiers can prevent paraffin deposition at temperatures close to WAT at concentrations of 50-200 ppm. Additives co-crystallize with wax crystals through van der Waals interaction. Modified polymers create a steric hindrance to the wax crystals that prevent the proper alignment of the new incoming paraffin molecules and the growth [20]. 
Table 2. Pour point of waxy crude oils in the South Turgay basin after heat and PPD treatments.

\begin{tabular}{llc}
\hline Waxy crude oil & \multicolumn{1}{c}{ Treatment } & PP $\left({ }^{\circ} \mathrm{C}\right)$ \\
\hline Akshabulak & Heat treatment & +18 \\
& EVA & +6 \\
& EVA-M & 0 \\
Aschysay & Heat treatment & +21 \\
& EVA & +15 \\
& EVA-M & +9 \\
Konys-Bektas & Heat treatment & +24 \\
& EVA & +12 \\
Kumkol & EVA-M & +6 \\
& Heat treatment & +12 \\
& EVA & +3 \\
& EVA-M & -3 \\
\hline
\end{tabular}

Table 3. Inhibition degree of waxy crude oils in the South Turgay basin.

\begin{tabular}{lccc}
\hline & $\mathrm{PP}\left({ }^{\circ} \mathrm{C}\right)$ & $m$ (wax), g & $\begin{array}{c}\text { Inhibition } \\
\text { degree }(\%)\end{array}$ \\
\hline Akshabulak & & & \\
$\quad$ Untreated & +21 & 3.6 & 0 \\
Heat treated & +18 & 2.48 & 31.2 \\
EVA & +6 & 1.85 & 48.5 \\
EVA-M & 0 & 1.13 & 68.7 \\
Aschysay & & & \\
Crude oil & +24 & 4.6 & 0 \\
Heat treated & +21 & 3.28 & 28.6 \\
EVA & +15 & 2.99 & 35.0 \\
EVA-M & +9 & 2.01 & 56.2 \\
Konys-Bektas & & & \\
Untreated & +24 & 4.2 & 0 \\
Heat treated & +21 & 3.12 & 25.8 \\
EVA & +9 & 2.85 & 32.1 \\
EVA-M & +3 & 1.58 & 62.3 \\
Kumkol & & & \\
Untreated & +15 & 3.4 & 0 \\
Heat treated & +12 & 2.11 & 37.8 \\
EVA & +9 & 1.95 & 42.5 \\
EVA-M & -3 & 0.95 & 72.0 \\
\hline
\end{tabular}

It should also be noted that copolymers based on ethylene-vinyl acetate, in contrast to other polymers, modify wax crystals with the formation of plate like (lamellate) structures. However, this synthetic additive inhibits the process of paraffin deposition. A key parameter in determination of EVA copolymer effectiveness is a vinyl acetate group content in the copolymer. Increase of vinyl-acetate content reduces crystallizing tendency and contributes to

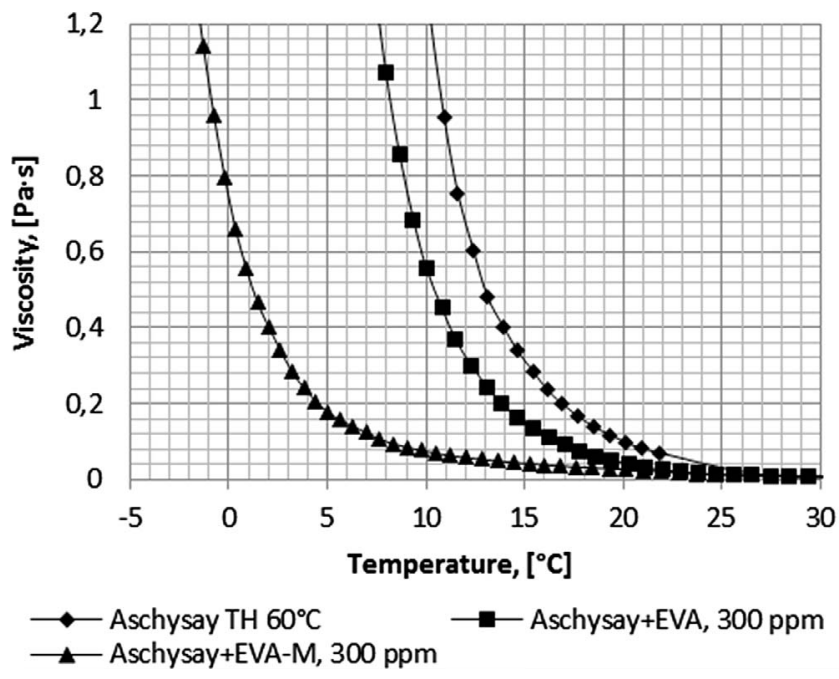

Fig. 2. Temperature dependence of dynamic viscosity at $\gamma=10 \mathrm{~s}^{-1}$ for Aschysay oil.

solubility due to the higher polarity. Partially hydrolyzed ethylene-vinyl acetate copolymer shows better results than the unmodified one. The side chains in vinyl-acetate groups destroy the process of wax crystallization by reducing WTA or pour point. However, a high content of vinyl-acetate reduces co-crystallization with paraffins and has an adverse effect on efficiency. Generally, about 25-30\% vinyl-acetate content in EVA gives the best results for improving flow of oil and paraffin inhibition [21].

\subsection{Influence of modified EVA on dynamic viscosity and shear stress of waxy crude oils}

The viscosity of crude oil is perhaps one of the most important physical properties. For most crude oils, at sufficiently high temperature, the viscosity at a given temperature is constant and the crude, although chemically very complex, is a simple Newtonian fluid. As the temperature is lowered, however, the flow properties of a crude oil can readily change from the simple Newtonian to very complex flow behavior due to the crystallization of waxes and the colloidal association of asphaltenes. The waxes basically consist of $n$-alkanes, which crystallize to form interlocking structures of plates and needles. These crystals can entrap the oil into a gel-like structure that is capable of forming thick deposits in pipes and increasing pumping pressures to the point where flow ceases [22].

According to the rheological behavior of oils in the South Turgay, it was identified that partially hydrolyzed EVA is an additive with the greatest efficiency to improve the rheological properties as dynamic viscosity and shear stress at positive temperatures for all tested oils. Figures 2-4 illustrate the response of dynamic viscosity for different temperatures at assigned shear rate of $10 \mathrm{~s}^{-1}$ in the absence and presence of additives.

From Figure 2 it can be observed that that at temperature $10{ }^{\circ} \mathrm{C}$ dynamic viscosity of oil treated with modified EVA (EVA-M) is $0.082 \mathrm{~Pa} \mathrm{~s}$, which is 15 times lower than 


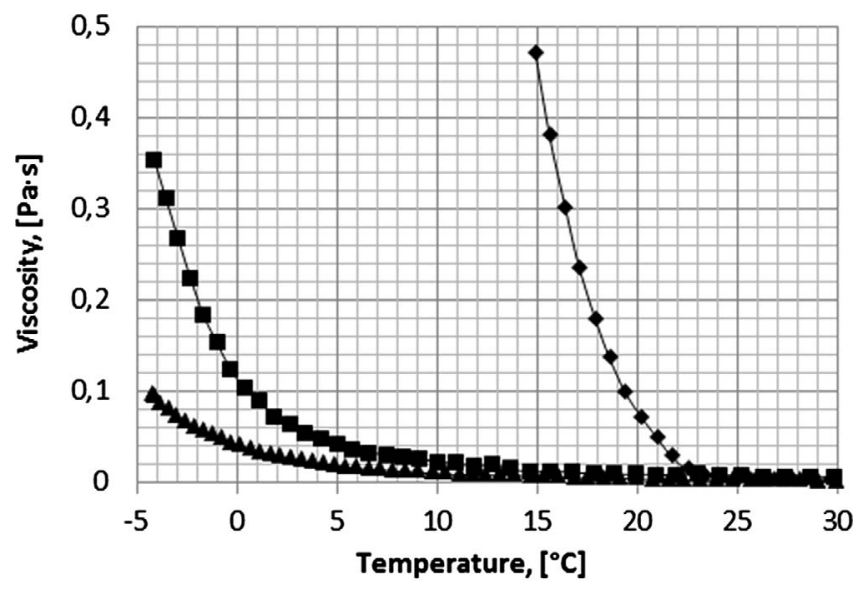

\section{—Akshabulak+EVA-M,300 ppm}

Fig. 3. Temperature dependence of viscosity at $\gamma=10 \mathrm{~s}^{-1}$ for Akshabulak oil.

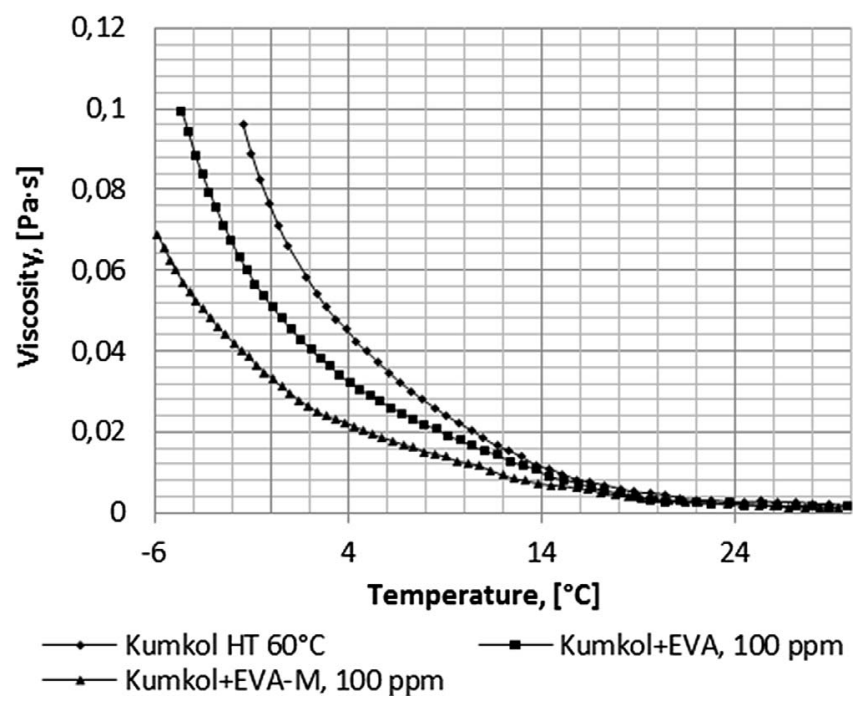

Fig. 4. Temperature dependence of dynamic viscosity at $\gamma=10 \mathrm{~s}^{-1}$ for Kumkol oil.

the viscosity of heat treated oil (1.23 Pa s). Treatments efficacy can be arranged as following for Aschysay oil: EVA-M (300 ppm), EVA, heat treatment.

The pattern of dynamic viscosity changes for Akshabulak oil is the same as for Aschysay with only slight discrepancy. This consists in slight reduction of rheological characteristics for oil after injection of EVA-M compared to this after EVA injection (Figs. 2-3). The optimal concentration of EVA-M for Akshabulak oil is $300 \mathrm{ppm}$. The rheological parameters of oil treated with EVA-M are 3-3.5 times lower than that for oil processed with EVA. Thus, viscosity of Akshabulak oil treated by EVA-M is $0.1 \mathrm{~Pa}$ s at $-5^{\circ} \mathrm{C}$, which shows its efficacy.

Moreover, EVA affects rheological behavior of this oil type in the same manner at positive temperatures. However, there is significant discrepancy in the effectiveness of two additives at negative temperatures. Particularly, modified copolymer represents lower viscosity than EVA. It should be noted that the dynamic viscosity of heat treated oil at $20{ }^{\circ} \mathrm{C}$ began to sharply increase, whereas EVA-M shows considerable increase in these properties only at $0{ }^{\circ} \mathrm{C}$.

Thus, temperature of the oil's flow transition from Newtonian to non-Newtonian model after injection of the PPD is reduced from $15{ }^{\circ} \mathrm{C}$ (for Konys-Bektas without additive) to $4{ }^{\circ} \mathrm{C}-2{ }^{\circ} \mathrm{C}$. The pour point is lowered to from $18{ }^{\circ} \mathrm{C}$ to $0{ }^{\circ} \mathrm{C}$ and $-3{ }^{\circ} \mathrm{C}$. Viscosity is reduced approximately 10 times.

From Figure 4, it can be seen that Kumkol oil with modified PPDs (EVA-M) reduce the dynamic viscosity better than EVA. The viscosity is reduced 2.4 times compared to the heat-treated oil at $0{ }^{\circ} \mathrm{C}(0.32-0.32 \mathrm{~Pa} \mathrm{~s})$.

It also should be pointed out that in general the viscosity of the heavy crude oil depends on the shear rate. The viscosity reaches low values at high shear rates. This means that the flow encounters less resistance at higher shear rates. This is due to the molecular chains found in the heavy crude oil. As the shear rate increases, the chain type molecules disentangled, stretched, and reoriented parallel to the driving force, and hence reduced the heavy crude oil viscosity [23].

Dynamic viscosity changes are tabulated in Table 4.

Overall, conducted rheological measurements on dynamic viscosity change reveal that EVA-M copolymer has a good compatibility with crude oils and thereby can be referred as an effective flow improver.

\subsection{Influence of modified PPD on transition of waxy crude oils from Newtonian to non-Newtonian}

Examination of oil from oil fields in the South Turgay basin has been carried out according to obtained flow and viscosity curves.

Additive injection into heat-treated oil and the subsequent cooling leads to the wax crystal formation process, resulting in formation of modified paraffin agglomerates, mostly lamellar (plate like) form. In this case, oil has a better aggregate stability and transfers to a non-Newtonian fluid at low temperatures. Flow curves are constructed according to equations of Newton, Ostwald and HerschelBulkley

Newton model:

$$
\tau=\eta \gamma,
$$

where $\eta$ - Newtonian viscosity, $\gamma$ - shear rate.

Ostwald model:

$$
\tau=\eta \gamma^{p},
$$

where $\eta$ - plastic viscosity, $\gamma$ - shear rate, $p$ - coefficient of a non-Newtonian fluid.

Herschel-Bulkley model:

$$
\tau=\tau_{0}+\eta \gamma^{p},
$$

where $\tau_{0}$ - critical shear stress (yield strength), $\eta$ - coefficient of fluidity, and $p$ - coefficient of a non-Newtonian fluid.

According to the graph of the stress shear and dynamic viscosity dependences of critical shear stress (yield point) 
Table 4. Dynamic viscosity changes of waxy crude oils in the South Turgay basin after heat and additive treatments.

\begin{tabular}{lllll}
\hline Waxy crude oil & Treatment & \multicolumn{3}{c}{ Dynamic viscosity (Pa s) } \\
\cline { 3 - 5 } & & $10{ }^{\circ} \mathrm{C}$ & $20{ }^{\circ} \mathrm{C}$ & $30{ }^{\circ} \mathrm{C}, 10^{-2}$ \\
\hline Akshabulak & Heat treatment & 1.590 & 0.071 & 0.23 \\
& EVA & 0.010 & 0.005 & 0.093 \\
EVA-M & 0.009 & 0.004 & 0.014 \\
Aschysay & Heat treatment & 1.220 & 0.095 & 0.895 \\
Konys-Bektas & EVA & 0.557 & 0.041 & 0.879 \\
& EVA-M & 0.069 & 0.027 & 0.777 \\
Kumkol & Heat treatment & 4.24 & 0.084 & 1.240 \\
& EVA & 0.052 & 0.015 & 0.832 \\
& EVA-M & 0.045 & 0.012 & 0.787 \\
& Heat treatment & 0.020 & 0.005 & 0.176 \\
\hline
\end{tabular}

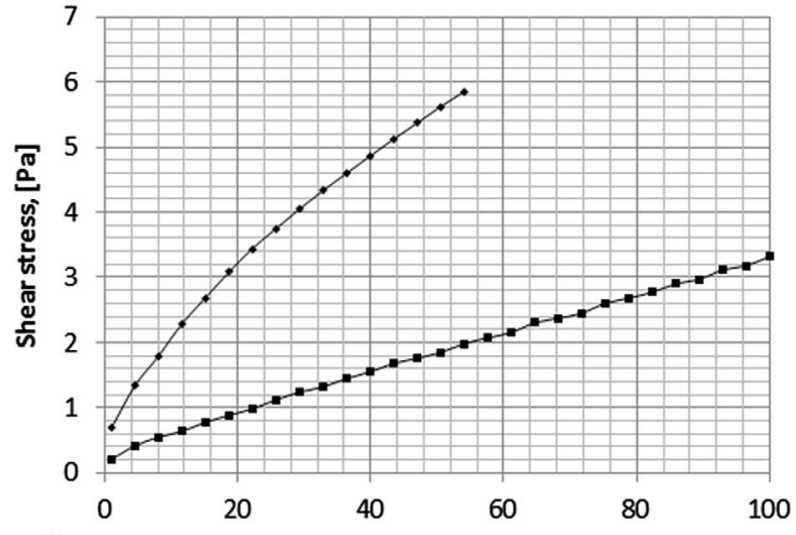

a) Shear rate, [s-']

$\longrightarrow$ Aschysay $\mathrm{HT}\left(15^{\circ} \mathrm{C}\right) \quad \longrightarrow$ Aschysay+EVA-M, $\left(15^{\circ} \mathrm{C}\right)$

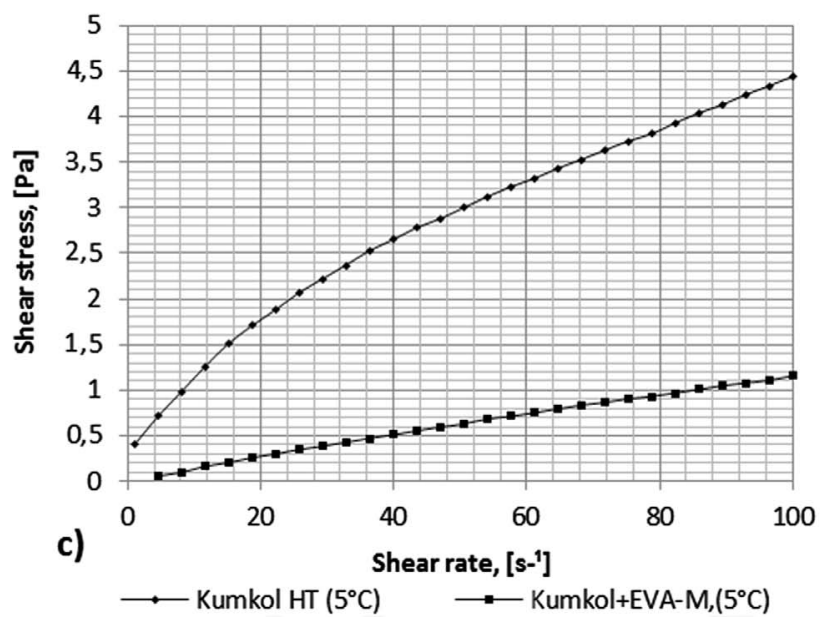

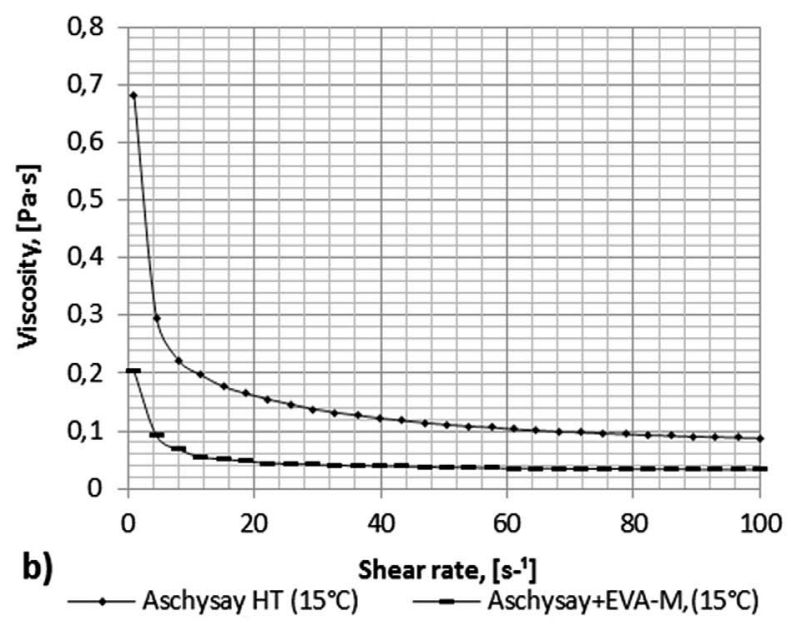

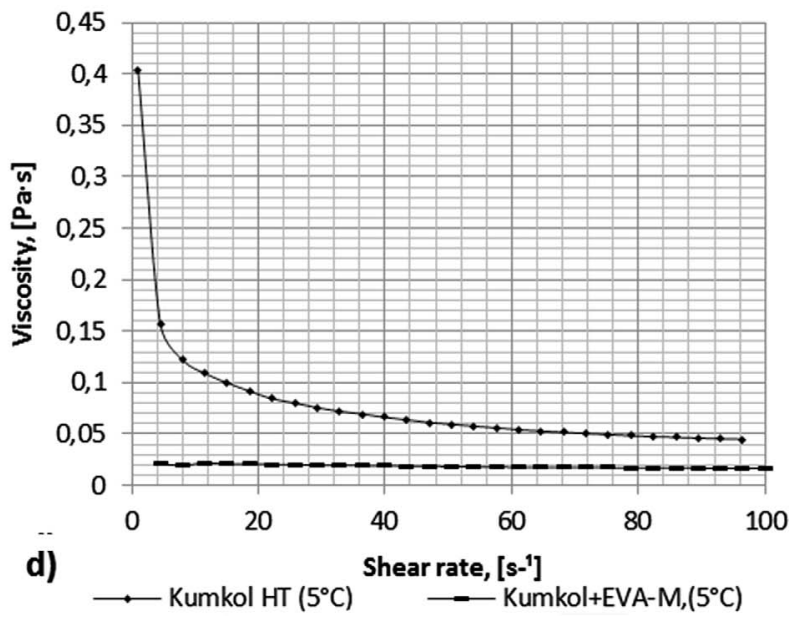

Fig 5. Comparison flow curve of Aschysay (a) and (b) and Kumkol (c) and (d) oil with HT and PPD EVA-M. 
Table 5. - Rheological parameters for Akshabulak waxy oil at a shear rate of $2-100 \mathrm{~s}^{-1}$ in the temperature range from $5{ }^{\circ} \mathrm{C}$ to $25^{\circ} \mathrm{C}$.

\begin{tabular}{lcccccccr}
\hline T $\left({ }^{\circ} \mathrm{C}\right)$ & \multicolumn{2}{c}{ Flow equation } & \multicolumn{2}{c}{$\tau_{0}(\mathrm{~Pa})$} & \multicolumn{2}{c}{$\eta(\mathrm{Pa} \mathrm{s})$} & \multicolumn{2}{c}{$p$} \\
\cline { 2 - 9 } & HT $60{ }^{\circ} \mathrm{C}$ & EVA-M & HT $60{ }^{\circ} \mathrm{C}$ & EVA-M & HT $60{ }^{\circ} \mathrm{C}$ & EVA-M & HT $60{ }^{\circ} \mathrm{C}$ & EVA-M \\
\hline 25 & $\tau=\eta \gamma$ & $\tau=\eta \gamma$ & - & - & 0.007 & 0.005 & 1 & 1 \\
20 & $\tau=\eta \gamma^{p}$ & $\tau=\eta \gamma^{p}$ & - & - & 0.054 & 0.012 & 0.695 & 0.834 \\
15 & $\tau=\eta \gamma^{p}$ & $\tau=\eta \gamma^{p}$ & - & - & 0.856 & 0.032 & 0.339 & 0.849 \\
10 & $\tau=\tau_{0}+\eta \gamma^{p}$ & $\tau=\eta \gamma^{p}$ & 1.162 & - & 4.332 & 0.136 & 0.183 & 0.652 \\
5 & - & $\tau=\tau_{0}+\eta \gamma^{p}$ & 7.272 & 0.622 & - & 0.450 & - & 0.806 \\
\hline
\end{tabular}

and plastic (apparent) viscosity of oil were determined. From Figure 5 it can be seen that transition from Newtonian to non-Newtonian flow for heat-treated Aschysay oil is in the range of $10-25^{\circ} \mathrm{C}$.

It can be seen from Table 5 that all the investigated oils, in addition to Akshabulak oil, with heat treatment in the temperature range of $25-30^{\circ} \mathrm{C}$, are the Newton equation.

When the temperature is lowered to $20^{\circ} \mathrm{C}$, the flow of Akshabulak oils passes into a pseudo-plastic flow and the flow curve obeys the Ostwald equation:

$$
\tau=\eta \gamma^{p}
$$

where $\tau$ - shear stress, $\gamma$ - shear rate, $\eta$ - plastic viscosity, and $p$-exponent of the flow nonlinearity.

The pseudo-plastic flow of oil indicates the beginning of the structuring of oil into a weakly crosslinked gel. For Akshabulak oil this transition of the flow is observed at $15{ }^{\circ} \mathrm{C}$. As the temperature decreases, the flow of oil passes from the pseudo-plastic to the viscoplastic flow and is determined by the Herschel-Bulkley equation:

$$
\tau=\tau_{0}+\eta \gamma^{p},
$$

where $\tau$ - shear stress, $\tau_{0}$ - yield point, $\gamma$ - the shear rate, $\eta$ - plastic viscosity, and $p$ - exponent of the flow nonlinearity.

The transition to a viscoplastic flow indicates the continuation of the structuring with the formation of stronger gels, which causes the appearance of a limited yield point, which is one of the main parameters determining the limiting value of the shear stresses during the restart of the oil pipeline after a stop.

For thermally treated oils, the transition to a viscoplastic flow is observed for oil of Akshabulak at $15^{\circ} \mathrm{C}$; at the same time, the processing with the EVA-M additive reduces the temperature transition region of this flow for Akshabulak oil up to $5{ }^{\circ} \mathrm{C}$. For Akshabulak oil, the values of the yield point, when used an additive at $5{ }^{\circ} \mathrm{C}$ decrease sharply $(0.622 \mathrm{~Pa})$ compared to heat treated oil $(7.272 \mathrm{~Pa})$.

The values of the limiting shear stress, or yield point, of oils in the South Turgay basin are showed in Table 6. From the data obtained EVA-M copolymer is considered to be an additive that shows a significant performance in regulating the flow of oil at low temperatures. The transition temperature of oil condition lowers with the application of modified ethylene-co-vinyl acetate copolymer.
Table 6. Yield point and viscosity of oils in the South Turgay basin with and without additives.

\begin{tabular}{ccc}
\hline$T\left({ }^{\circ} \mathrm{C}\right)$ & $\tau_{0}(\mathrm{~Pa})$ & Viscosity $(\mathrm{Pa} \mathrm{s})$ \\
\hline Kumkol HT $60{ }^{\circ} \mathrm{C}$ & & \\
25 & 0 & 0.004 \\
20 & 0 & 0.005 \\
15 & 0 & 0.011 \\
10 & 0.08 & 0.063 \\
5 & 0.40 & 0.163 \\
0 & 1.62 & 0.489 \\
Kumkol + EVA-M, $300 \mathrm{ppm}$ & \\
20 & 0 & 0.005 \\
15 & 0 & 0.008 \\
10 & 0 & 0.013 \\
5 & 0 & 0.018 \\
0 & 0.05 & 0.028 \\
-5 & 0.12 & 0.083 \\
Aschysay HT $60^{\circ} \mathrm{C}$ & & \\
25 & 0 & 0.017 \\
20 & 0.14 & 0.048 \\
15 & 0.68 & 0.296 \\
10 & 3.00 & 1.126 \\
Aschysay + EVA-M & $300 \mathrm{ppm}$ & \\
25 & 0 & 0.015 \\
20 & 0.02 & 0.024 \\
15 & 0.20 & 0.092 \\
10 & 0.62 & 0.252 \\
5 & 4.01 & 1.293 \\
\hline
\end{tabular}

It should be pointed out that a significant improvement of rheological properties of waxy oil of Aschysay and Konys-Bektas and improvement of rheological behavior of Akshabulak oil, particularly, increasing of oil's aggregate stability and as a result increasing of rheological stability of oil over long time during storage and transportation have been accomplished. The effect of EVA-M copolymer additive in time is fairly stable, compared with the effect of the EVA. Determination of the stability and duration 
Table 7. Determination of the stability and duration of EVA-M and EVA additives on the rheological parameters of Akshabulak oil according to limiting shear stress (yield point) and viscosity depending on time.

\begin{tabular}{lcccc}
\hline Time (days) & \multicolumn{2}{c}{$\begin{array}{c}\tau_{0}-\text { yield point } \\
(\mathrm{Pa})\end{array}$} & \multicolumn{2}{c}{$\begin{array}{c}\text { viscosity } \\
(\mathrm{Pa} \mathrm{s})\end{array}$} \\
\cline { 2 - 5 } & $5{ }^{\circ} \mathrm{C}$ & $0{ }^{\circ} \mathrm{C}$ & $5{ }^{\circ} \mathrm{C}$ & $0{ }^{\circ} \mathrm{C}$ \\
\hline 1 day & & & & \\
$\quad$ EVA-M & 0.1122 & 1.0461 & 0.1107 & 0.2589 \\
EVA & 0.1131 & 1.1128 & 0.1340 & 0.2861 \\
3 days & & & & \\
EVA-M & 0.1042 & 0.4457 & 0.0728 & 0.2060 \\
EVA & 0.1258 & 0.8329 & 0.1089 & 0.3147 \\
7 days & & & & \\
EVA-M & 0.0306 & 0.4790 & 0.1148 & 0.4007 \\
EVA & 0.1416 & 0.8058 & 0.4624 & 0.9143 \\
14 days & & & & \\
EVA-M & 0.0463 & 0.7364 & 0.1425 & 0.5372 \\
EVA & 0.6762 & 1.8226 & 0.4824 & 1.2475 \\
\hline
\end{tabular}

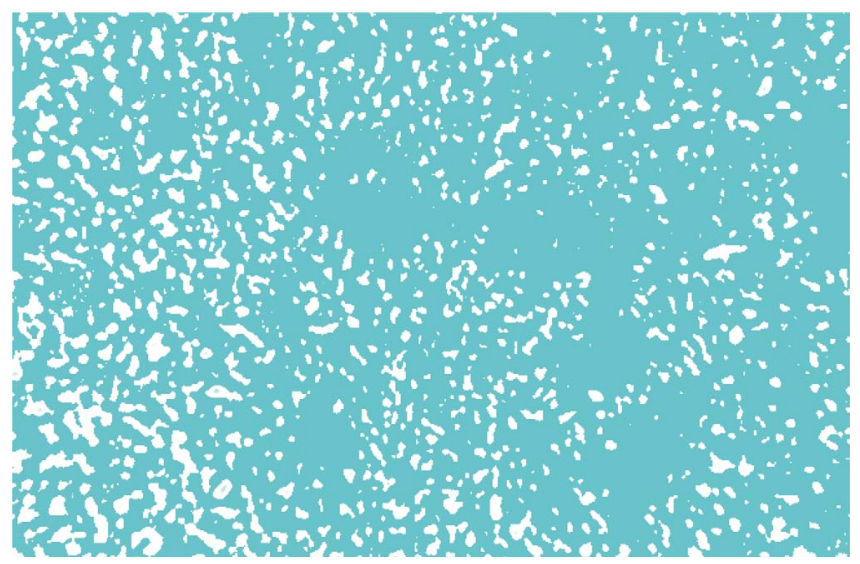

Fig. 6. Photomicrograph of Aschysay oil with EVA at $15^{\circ} \mathrm{C}$.

of EVA-M and EVA additives on the rheological parameters of Akshabulak oil according to limiting shear stress (yield point) and plastic viscosity depending on time is given in Table 7.

\subsection{The morphology of paraffin crystals in presence of EVA-M}

Plate like (lamellar) crystal structures of wax, resembling thin flat plate are observed in Figures 6-10. This phenomenon is due to the fact that the PPD EVA-M consists of two functional parts: ethylene (non-polar), acetate (polar) and hydroxyl group. Non-polar part of modified EVA attracts waxes presenting in crude oil, and formed paraffins co-crystallize with ethylene part of macromolecule with further formation of alternating layers. Polar part repels paraffin crystals of oil, thus preventing the formation

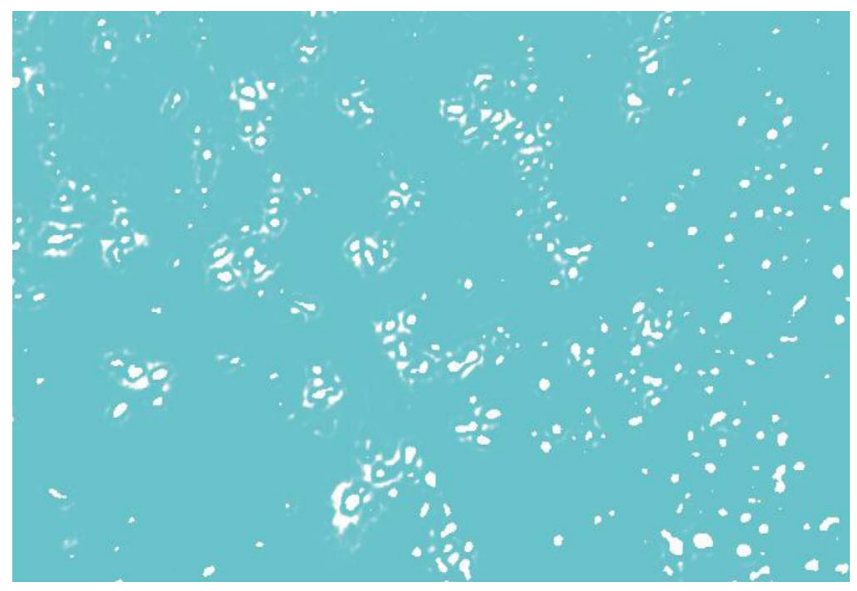

Fig. 7. Photomicrograph of Aschysay oil with EVA-M at $15^{\circ} \mathrm{C}$.

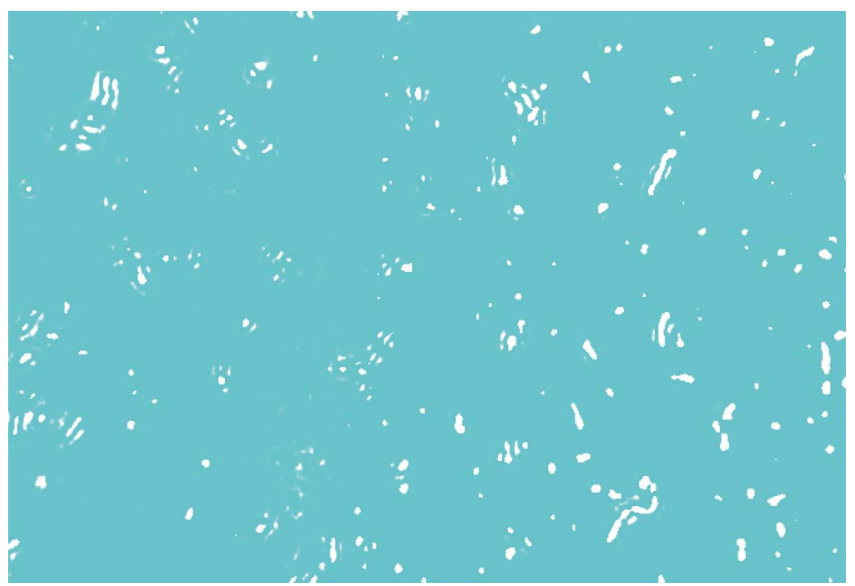

Fig. 8. Photomicrograph of Akshabulak oil with EVA-M at $5{ }^{\circ} \mathrm{C}$.

of large agglomerates of the wax crystals [24]. Polymer additive based on EVA does not disperse wax crystal structures, but plays a role of wax modifier. However, EVA-M shows high efficiency on improvement of waxy crude oils' rheological characteristics.

In Figures 6-10, photomicrographs of Aschysay and Akshabulak oil with modified and unmodified EVA at $15{ }^{\circ} \mathrm{C}$ and $5{ }^{\circ} \mathrm{C}$, were given. According to the photomicrographs, it can be seen that larger plate-like crystal structures are formed in case of unmodified EVA's application than modified EVA (EVA-M) with a concentration of $300 \mathrm{ppm}$. It can be seen from Figure 10 that, the crystal structure of Akshabulak oil at $5{ }^{\circ} \mathrm{C}$ without EVA is much larger than crystal structures of oil when we applied EVA and EVA-M. Moreover, Akshabulak oil at $5{ }^{\circ} \mathrm{C}$ easily solidified without adding any additives due to formation of various shapes of wax depositions [25, 26]. According to studies the morphology of the crystal structures of paraffins after the addition of modified EVA it should be concluded that the formation of plate-like structures is due to repellent of wax crystals by the polar acetate group in EVA copolymer that prevent the formation of large agglomerates of 


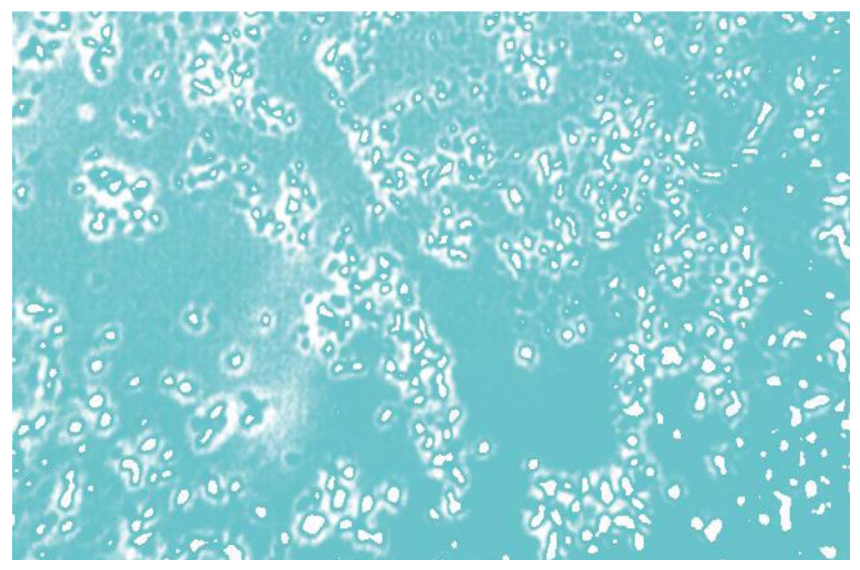

Fig. 9. Photomicrograph of Akshabulak oil with EVA at $5{ }^{\circ} \mathrm{C}$.

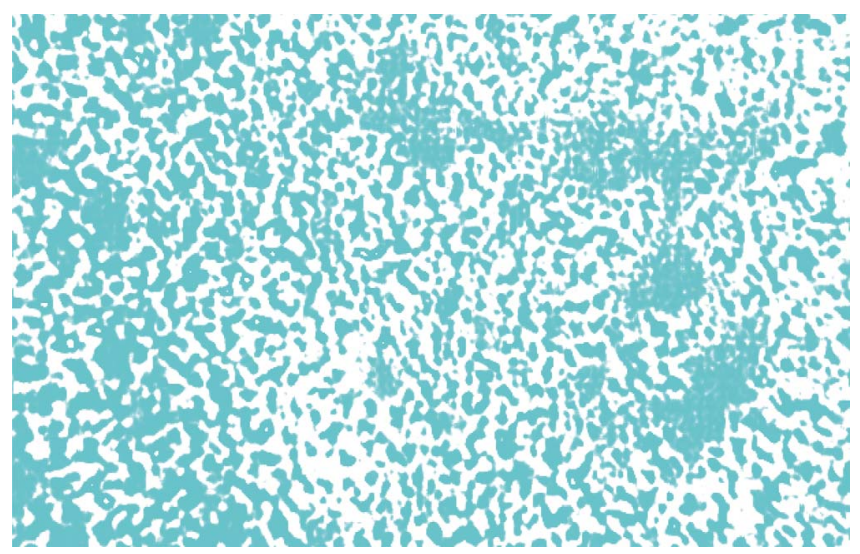

Fig. 10. Photomicrograph of Akshabulak oil at $5{ }^{\circ} \mathrm{C}$, without EVA.

aggregate stability. This phenomenon leads to the inhibition of wax deposition.

\section{Conclusion}

The rheological behavior of four oil samples of the South Turgai through using PPD EVA with VA content 25\%, followed by modification by hydrolysis of VA groups, was investigated. It is shown that, depending on their nature, oil has a different response to the effect of PPD. And PPD EVA-M significantly improves the rheological behavior of oils. It is also shown that crude oils with PPD have a low transition temperature of the Newtonian flow (ideal), Ostwald (pseudoplastic) and Herschel-Bulkley (viscoelastic). To determine the effectiveness of EVA-M, the experiments were performed with EVA-M, EVA and heat treatment. The performances of PPD (EVA-M) in pour point, inhibition degree, dynamic viscosity, shear stress at various temperatures were studied. The results showed that in all these parameters EVA-M showed better results than EVA and heat treatment. It was also determined that modified poly(ethylene-co-vinyl acetate) (EVA-M) inhibit and reduce the wax deposition while the other inhibitors like EVA and heat treatment methods were not effective for this propose.

Acknowledgments. The authors gratefully acknowledge the financial support from the Ministry of Education and Science of the Republic of Kazakhstan (Project No. BR05236800, Contract No. 208, March 19, 2018).

\section{References}

1 Kozhabekov S.S., Aldyarov T.K., Diduh A.G. (2004) Investigation of wax precipitation in pipeline of PavlodarShymkent, Oil Gas Kazakhstan 4, 99-106 (in Russian).

2 Misra S., Baruah S., Singh K. (1995) Paraffin problems in crude oil production and transportation: A review, SPE Prod. Facil. 10, 1, 50-54.

3 Soni H.P., Bharambe D.P. (2008) Performance-based designing of wax crystal growth inhibitors, Energy Fuels 22, 3930-3938.

4 Yang F., Zhao Y., Sjöblom J., Li C., Paso K.G. (2015) Polymeric wax inhibitors and pour point depressants for waxy crude oils: A critical review, J. Dispers. Sci. Technol. 36, 2, 213-225.

5 Barbosa Junior W., Silva D.N., Souza C.P., Oliveira H.N.M., Moraes J.E.F., Chiavone Filho O. (2007) Phase changes of petroleum mixtures by monitoring temperature and conductivity for paraffin formation, Braz. J. Pet. Gas 1, 34-44.

6 Guozhong Z., Gang L. (2010) Study on the wax deposition of waxy crude in pipelines and its application, J. Pet. Sci. Eng. $\mathbf{7 0}, 1-9$.

7 Tabzar A., Fathinasab M., Salehi A., Bahrami B., Mohammadi A.H. (2018) Multiphase flow modeling of asphaltene precipitation and deposition, Oil Gas Sci. Technol. - Rev. IFP Energies nouvelles 73, 51.

8 Chanda D., Sarmah A., Borthakur A., Rao K.V., Subrahmanyam B., Das H.C. (1998) Combined effect of asphaltenes and flow improvers on the rheological behavior of Indian waxy crude oil, Fuel 77, 11, 1163-1167.

9 Chanda D., Sarmah A., Borpthakur A., Rao K.V., Subrahmanyam B., Das H.C. (1996) Alkyl fumarate-vinyl acetate copolymer as flow improver for high waxy Indian crude oil, Energy Fuels 10, 844-848.

10 Jafari Behbahani T., Golpasha R., Akbarnia H., Dahaghin A. (2008) Effect of wax inhibitors on pour point and rheological properties of Iranian waxy crude oil, Fuel Process. Technol. 89, 973-977.

11 Machado A.L.C., Lucas E.F. (2002) Influence of ethyleneco-vinyl acetate copolymers on the flow properties of wax synthetic systems, J. Appl. Polym. Sci. 85, 1337-1348.

12 Andre Luiz de Castro Machado I.Z., Elizabete F., Lucas Z. (1999) Poly(ethylene-co-vinyl acetate) (eva) copolymers as modifiers of oil wax crystallization, Pet. Sci. Technol. 17, 1029-1041.

13 Oliveira G.E., Mansur C.R.E., Lucas E.F., Gonzalez G., de Souza W.F. (2007) The effect of asphaltenes, naphthenic acids, and polymeric inhibitors on the pour point of paraffins solutions, J. Dispers. Sci. Technol. 28, 349-356.

14 Wu L.-J., Zhang F., Guan Z.-Y., Guo S.-F. (2008) Synthesis of new EVA graft copolymer and its pour point depressant performance evaluation for Daqing crude oil, J. Cent. South Univ. Technol. 15, 488-491. 
15 Ren Y., Chen Z., Hui D., Fang L., Zhang X. (2017) Preparation and evaluation of modified ethylene-vinyl acetate copolymer as pour point depressant and flow improver for Jianghan crude oil, Ind. Eng. Chem. Res. 56, 11161-11166.

16 Machado A.L., Lucas E.F. (1999) Poly (ethylene-co-vinyl acetate) (EVA) copolymers as modifiers of oil wax crystallization, Pet. Sci. Technol. 17, 1029-1041.

17 Kozhabekov S.S., Boranbaeva L.Y., Didukh A.G., Alexeev S.G. (2005) Commercial oil and oil mixture, transported by pipeline network of the Republic of Kazakhstan, $403 \mathrm{p}$.

18 Alvares Dellyo, Lucas E.F. (2000) Chemical structure effect of (meth) acrylic ester copolymers and modified poly (ethylene-co-vinyl acetate) copolymer on paraffin deposition prevention in crude oil, Pet. Sci. Technol. 18, 195-202.

19 Soni H.P., Kiranbala, Bharambe D.P. (2008) Performancebased designing of wax crystal growth inhibitors, Energy Fuels 22, 3930-3938.

20 Kelland M.A. (2009) Production Chemicals for Oil and Gas Industry, CRC Press, USA. (Chapter 10).
21 Machado L., Lucas E.F. (2002) Influence of ethylene-co-vinyl acetate copolymers on the flow properties of wax synthetic systems, J. Appl. Polym. Sci. 85, 1337.

22 Elsockary M.A., Kandil O.F., Mohamed Z.M. (2008) Using of modified plastic waste based on poly(ethylene-co-acrylic acid) grafts to solve transportation problem of petroleum crude oil, J. Dispers. Sci. Technol. 29, 7-19.

23 Ghannam M.T., Esmail N. (1997) Rheological properties of carboxymethyl cellulose, J. Appl. Polym. Sci. 64, 289-301.

24 Ashbaugh H.S., Guo X., Schwahn D., Prud'homme R.K., Richter D., Fetters L.J. (2005) Interaction of paraffin wax gels with ethylene vinyl acetate co-polymers, Energy Fuels 19, 138-144.

25 Duan J., Li J., Liu H., Gu K., Guan J., Xu S., Gong J. (2018) A model of wax deposition under oil-gas two-phase stratified flow in horizontal pipe, Oil Gas Sci. Technol. - Rev. IFP Energies nouvelles $\mathbf{7 3}, 80$.

26 Eyni L., Assareh M., Ayatollahi S., Ranjbaran M. (2018) An improved modeling approach for asphaltene deposition in oil wells including particles size distribution, Oil Gas Sci. Technol. - Rev. IFP Energies nouvelles 73, 25. 